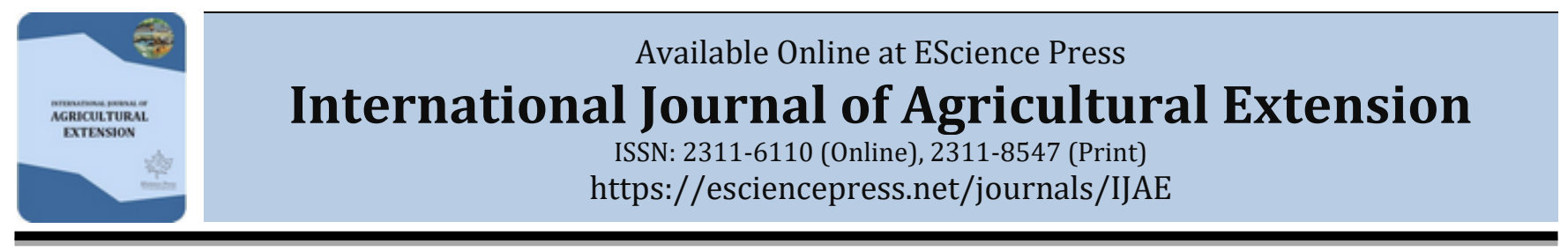

\title{
DETERMINANTS OF TOBACCO CULTIVATION IN KUSHTIA DISTRICT, BANGLADESH
}

Md. Zulfiquer Rahman, Muhammad H. Kabir, Md. Mahbubul Alam, Md. Saiful Islam* Department of Agricultural Extension \& Information System, Sher-e-Bangla Agricultural University, Dhaka, Bangladesh.

* Corresponding Author Email: mdsaiful.sumon52@gmail.com

\section{A B S T R A C T}

The study was undertaken to assess the extent of area used for tobacco cultivation and to determine some selected characteristics of tobacco farmers that significantly influence farmers' cultivation of tobacco. The selected characteristics were- age, education, farm size, annual income, tobacco cultivation experience, family labor, time spent in tobacco cultivation, profitability, agent contact, input availability, level of pest infestation and market security perception. The study was conducted at three villages of Mirpur upazilla under Kushtia district with the help of an interview schedule from September 12 to October 3, 2018. Twenty five percent (25\%) of the farmers were randomly selected from a population of 424 tobacco farmers. Out of the total population, 106 tobacco farmers were selected as the sample of the study. Multiple linear regressions were used in order to identify the important factors for tobacco cultivation. The findings also revealed that age, education, annual income, family labor and agent contact have significant positive contribution on tobacco cultivation. Therefore, to reduce tobacco cultivation area coverage by the farmers, policy should be made through giving emphasize on the significant factors.

Keywords: Determinants, Tobacco, Cultivation, Kushtia district, Bangladesh.

\section{INTRODUCTION}

Bangladesh, one of the developing countries consumes a significant portion of tobacco in the world. Tobacco in Bangladesh is being cultivated from the ancient time however nowadays commercial tobacco farming is a under debate. Tobacco was introduced in mid-sixties of the last century into the fields where food crops were grown, and more widely after liberation in 1971 by the British American Tobacco Company in Teesta silt in Rangpur area (Sarkar \& Haque, 2001). Although Bangladesh Agricultural Research Institute (BARI) has conducted research and development activities of tobacco however abandoned in 1995, tobacco production has mainly been pushed by big multinational companies such as British American Tobacco Company through contract growers (Sarkar \& Haque, 2001).

Tobacco is a non-nutritious food and tobacco raw material for any industry is not suitable for the well-being of human. Tobacco products and its associated items such as cigarette, biri and other uses of tobacco are injurious to human health (Motaleb \& Irfanullah, 2011). On the other hand, the tobacco cultivation areas are still less than only $0.25 \%$ of the total land as compared to all crop production in Bangladesh. Considerably, there was only $0.22 \%$ land of all agricultural production by tobacco in 2009 (FAO, 2010). In the context of tobacco cultivation, tobacco is mostly dealt as one of the major cash crops which are mostly grown in areas like Rangpur, Chattogram hill tract region, greater Kushtia (Meherpur, Kushtia, Chuadanga), Jashore and Gazipur. Besides, this is extending to Rajshahi, Jhenaidah, Nilphamari, Lalmonirhat and even in Manikganj and Tangail district.

Employment in tobacco farming accounts for less than $0.5 \%$ of agricultural employment in Bangladesh. Bangladesh has become a net exporter in recent years, exporting about one-third of the tobacco grown (Barakat et al., 2012). Export of tobacco leaves from Bangladesh is a relatively new phenomenon, but it is becoming an expanding agricultural export. Starting from a very low or non-existent base, at more than $\$ 80$ million, raw tobacco export is the 
most important agricultural export after jute in terms of value. On the past, government efforts in the form of increased export incentives and active participation of the tobacco industry with access to foreign markets have contributed to the gradual growth of this sector in recent years. However, the sector has not been without controversy. Since 2008, Government has reversed its policy towards tobacco by withdrawing the cash incentives provided to exporters and imposing duty on export of tobacco leaf (Policy Research Institute of Bangladesh, 2012). The most important fact that needs to be recognized about tobacco is that it is a non-food crop -- it is not even a raw material for an industry that is necessary for the people of country. What it produces such as cigarette, biri and other products are harmful and injurious to health. It is also not a 'cash crop' for farmers as the term is commonly understood. It is one of the very few crops in the world entering the world trade entirely as leaf. It is green from the planting time to the harvesting time, with no change in its green color. This is why the company uses the slogan "Sobujer Somaroho" (the abundance of green) in order to deceive since such a green plant has absolutely no ecological and economic value in the local or domestic market. It is a crop that has only one market, i.e. the tobacco companies and their agents and they are interested in the leaves which they grade for quality and therefore decide the price. The company purchases only the leaves that are grown. The rest of the plant remains on the ground and does more harm to the soil.

It is clear from above discussion that tobacco cultivation has both positive and negative side. However, negative sides are higher than positive. Its production and use thus might raise ethical questions from normative point of view. Tobacco production has been expanded significantly in the country. According to BBS, although the total tobacco acreage has decreased the overall tobacco production has risen by $76 \%$ and $134 \%$ respectively during the period from 2007-08 to 2014-15 (BBS, 2016). Kushtia is a district of Khulna division of Bangladesh, is one of the hotspots where tobacco farming is popular. In recent years, a significant amount of cultivable land is being used for tobacco farming in this district. In Kushtia district the production rate of tobacco is highest among the all parts of the country in last 5 years. In Kushtia district 36443 acres land used for tobacco cultivation in 2015-2016 and the production is 31462 MT which is the biggest comparing to all other districts (Yearbook of Agricultural Statistics, 2016). In this situation farming of non-food crops like tobacco by replacing food-crop land is a threat on our food security. In this area, tobacco farming is also causing threat to health, environment and society.

The researcher was interested to conduct a study to identify determinants of extent of tobacco cultivation area with the emphasis on following specific objectives;

- To describe the selected characteristics of tobacco farmers

- To assess the extent of area used for tobacco cultivation; and

- To determine the characteristics that significantly influences farmers' cultivation of tobacco.

\section{METHODOLOGY}

Study area, population and sampling: Three villages namely Kabarbaria and chuniapara of Baruipara Union and Kistopur of Phulbaria union under Mirpur upazila of Kushtia district were selected as the locale of the study. The site is located at about $16 \mathrm{~km}$ west of Kushtia sadar. Agriculture was the major occupation in the study area and the area had well accessibility through road and water ways. Few were service holders and businessmen. Those three villages there had 424 register tobacco farmers who constituted the population for this study. Twenty five percent (25\%) of the farmer were selected for sample of the study (Rakib et al., 2018). Thus, 106 farmers constituted the sample for this study. Proportionate random sampling was followed to determine the number of farmers from three villages. Simple random sampling was followed to select sample for interview. However, a reserve list of 10 farmers was also prepared.

Farmers in the reserve list were used only when a respondent in the original list was not available. The distribution of population and sample was shown in Table 1.

Data collection methods: In order to collect desired information, an interview schedule was prepared keeping the objectives of the research in view. Farmers opinion-based question have been included in the schedule along with the selected characteristics of the respondents. It may be recalled that the schedules were pre-tested in actual field situation before using the same for final collection of data among 12 respondents of the study area. Necessary correction, additions and alterations were made in the interview schedule on the basis of results of pre-test. 
Table 1. Distribution of the population, sample and reserve list.

\begin{tabular}{lccc}
\hline Name of village & Population size & Number of tobacco farmers selected & Reserve list \\
\hline Kabarbaria & 53 & 13 & 1 \\
Chuniapara & 168 & 42 & 4 \\
Kistopur & 203 & 51 & 5 \\
Total & 424 & 106 & 10 \\
\hline
\end{tabular}

Data were collected personally by the researcher himself from the sample by using interview schedule. Data collection was started on September 12 and completed on October 3, 2018. Very good co-operation was obtained from the field extension workers and the local leaders. Data obtained from the respondents were transferred to the master sheet and then compiled to facilitate tabulation. The qualitative data were converted into quantitative one by means of suitable scoring techniques.

Measurement of Independent Variables: Considering individual, economic, social and mental components of the farmers, time and assets accessibility to the researcher, checking on applicable writing and talking about with pertinent specialists, we selected twelve characteristics of the respondents as the independent variables. These are age; education, farm size, annual income, tobacco cultivation experience, family labor, time spent in tobacco farming, profitability, agent contact, input availability, level of pest infestation and market security.

Measurement of Dependent Variable: Tobacco cultivation area was the dependent variable of the study. Tobacco cultivation area refers to the area that was cultivated by a tobacco farmer in a season. Tobacco cultivated area was measured by the amount of area which was under cultivation of tobacco by a farmer in two recent consecutive year. The mean value of those two years was taken as score.

Tobacco cultivation area $=$ $\frac{\text { Area used in } 2016+\text { Area used in } 2017}{2}$

Data Processing and Analysis: The analysis was done using SPSS (Statistical Package for Social Science) computer package. Descriptive analysis such as range, frequency count, number and percentage, mean, standard deviation and rank order were used. Multiple linear regressions were used in order to identify the important factors for tobacco cultivation. Throughout the study, five percent $(0.05)$ level of probability was used as a basis of rejecting a null hypothesis. The regression equations is as follows-

$\mathrm{Yi}=\mathrm{a}+\mathrm{b}_{1} \mathrm{X}_{1}+\mathrm{b}_{2} \mathrm{X}_{2}+\mathrm{b}_{3} \mathrm{X}_{3}+\mathrm{b}_{4} \mathrm{X}_{4}+\mathrm{b}_{5} \mathrm{X}_{5}+\mathrm{b}_{6} \mathrm{X}_{6}+\mathrm{b}_{7} \mathrm{X}_{7}+\mathrm{b}_{8} \mathrm{X}_{8}$ $+b_{9} x_{9}+b_{10} x_{10}+b_{11} x_{11}+b_{12} x_{12}+e$

Where, $\mathrm{Yi}$ is the tobacco cultivation area; $\mathrm{x} 1$ is their age; $\mathrm{x}_{2}$ is educational background; $\mathrm{x}_{3}$ is farm size; $\mathrm{x}_{4}$ is annual income; $\mathrm{x}_{5}$ is tobacco cultivation experience; $\mathrm{x}_{6}$ is family labor; $\mathrm{x}_{7}$ is time spent in tobacco farming; $\mathrm{x}_{8}$ is profitability; $\mathrm{x}_{9}$ is agent contact, $\mathrm{x}_{10}$ is input availability; $\mathrm{x}_{11}$ is level of pest infestation and $\mathrm{x}_{12}$ is market security, $b_{1}, b_{2}, b_{3}, b_{4}, b_{5}, b_{6}, b_{7}, b_{8}, b_{9}, b_{10}, b_{11}$ and $b_{12}$ are regressions coefficients of the corresponding independent variable, and " $\mathrm{e}$ " is random error, which is normally and independently distributed with zero (0) mean and constant variance.

\section{RESULTS AND DISSCUSSION}

Socio-economic characteristics of the respondents: This section deals with the description of selected characteristics of the respondents which were assumed to be associated with tobacco cultivation.

Twelve characteristics of the respondents which constituted as independent variables were selected to describe and to find out their contribution in tobacco cultivation area. Descriptive statistics is presented in Table 2.

Data presented in Table 2, revealed that $64.2 \%$ of the farmers were middle aged and $44.4 \%$ of the farmers had were in primary level of education. About $84.9 \%$ of the farmers had small farm size and $67 \%$ of the farmers had medium annual family income, while $63.21 \%$ of the respondents had medium experience in tobacco cultivation and $55.7 \%$ of the farmers had medium family labor. Table also showed that $75.47 \%$ of the farmers spent high time in tobacco cultivation and $75.47 \%$ of the respondents had medium profit from tobacco cultivation. About half of the farmers had medium contact with agent and $94.3 \%$ of the farmers had high input availability whereas $45.3 \%$ of the farmers had medium level of pest infestation and $90.6 \%$ of the farmers had high market security. 
Table 2. Socio-economic attributes of the respondents.

\begin{tabular}{|c|c|c|c|c|c|c|c|}
\hline \multirow{2}{*}{$\begin{array}{l}\text { Variables } \\
\text { (Measuring unit) }\end{array}$} & \multicolumn{2}{|c|}{ Range } & \multirow{2}{*}{ Categories } & \multicolumn{2}{|c|}{ Respondents } & \multirow{2}{*}{ Mean } & \multirow{2}{*}{ SD } \\
\hline & Minimum & Maximum & & Number & Percent & & \\
\hline \multirow{3}{*}{ Age (Years) } & & & Young (up to 35) & 31 & 29.2 & & \\
\hline & 20 & 60 & Middle (36-50) & 68 & 64.2 & 39.04 & 7.14 \\
\hline & & & Old (more than 50) & 7 & 6.6 & & \\
\hline \multirow{5}{*}{$\begin{array}{l}\text { Education (Years of } \\
\text { success schooling) }\end{array}$} & \multirow{5}{*}{0} & \multirow{5}{*}{12} & Illiterate $(0)$ & 2 & 1.9 & \multirow{5}{*}{2.8} & \multirow{5}{*}{2.84} \\
\hline & & & Can sign only (0.5) & 45 & 42.4 & & \\
\hline & & & Primary education (1-5) & 47 & 44.4 & & \\
\hline & & & Secondary education (6- & 10 & 9.4 & & \\
\hline & & & $\begin{array}{l}\text { 10) } \\
\text { Above secondary }(>10)\end{array}$ & 2 & 1.9 & & \\
\hline \multirow[t]{3}{*}{ Farm size (Ha) } & \multirow{3}{*}{0.21} & \multirow{3}{*}{2.81} & Marginal (up to 0.2 ha) & 1 & 0.9 & \multirow{3}{*}{0.64} & \multirow{3}{*}{0.46} \\
\hline & & & Small (0.21-1.0 ha) & 90 & 84.9 & & \\
\hline & & & Medium (1.01-3.0 ha) & 15 & 14.2 & & \\
\hline \multirow{3}{*}{$\begin{array}{l}\text { Annual income } \\
\text { ('000' Tk.) }\end{array}$} & \multirow{3}{*}{97} & \multirow{3}{*}{493} & Low (up to 200) & 30 & 28.3 & \multirow{3}{*}{246.51} & \multirow{3}{*}{78.43} \\
\hline & & & Medium (201-400) & 71 & 67 & & \\
\hline & & & High (above 400) & 5 & 4.7 & & \\
\hline \multirow{3}{*}{$\begin{array}{l}\text { Tobacco cultivation } \\
\text { experience (Years) }\end{array}$} & \multirow{3}{*}{3} & & Low (up to 13) & 14 & 13.21 & & \\
\hline & & 40 & Medium (14-26) & 67 & 63.21 & 20.92 & 7.34 \\
\hline & & & High (above 26) & 25 & 23.58 & & \\
\hline Family labor & & & Low $(<4)$ & 44 & 41.5 & & \\
\hline (Person) & 2 & 11 & Medium (4-7) & 59 & 55.7 & 4.08 & 1.75 \\
\hline & & & $\operatorname{High}(>7)$ & 3 & 2.8 & & \\
\hline Time spent in & & & Low (up to 21) & 1 & 0.94 & & \\
\hline tobacco cultivation & 21 & 63 & Medium (22-42) & 25 & 23.59 & 54.81 & 10.43 \\
\hline (Hours/week) & & & Much (above 42) & 80 & 75.47 & & \\
\hline & & & Low $(<1.50)$ & 19 & 17.93 & & \\
\hline Profitability & 1.20 & 2.70 & Medium (1.51- 2.0) & 80 & 75.47 & 1.73 & 0.23 \\
\hline (Score) & & & High $(>2.00)$ & 7 & 6.60 & & \\
\hline Agent contact & & & No contact $(0)$ & 19 & 17.93 & & \\
\hline (Score) & & & Low (1-23) & 4 & 3.77 & & \\
\hline & 0 & 70 & Medium (24-46) & 53 & 50 & 34.61 & 19.60 \\
\hline & & & High (above 46) & 30 & 28.30 & & \\
\hline Input availability & & & Not available (0) & 0 & 0 & & \\
\hline (Score) & 2 & 3 & Less available (1) & 0 & 0 & 204 & \\
\hline & 2 & 3 & Moderately available (2) & 6 & 5.7 & 2.94 & 0.23 \\
\hline & & & Highly available (3) & 100 & 94.3 & & \\
\hline Level of pest & & & Very low (1) & 13 & 12.3 & & \\
\hline infestation (Score) & 1 & & Low (2) & 38 & 35.8 & & \\
\hline & 1 & 4 & Medium (3) & 48 & 45.3 & 2.46 & 0.79 \\
\hline & & & High (4) & 7 & 6.6 & & \\
\hline Market security & & & Low (1) & 0 & 0 & & \\
\hline (Score) & 2 & 3 & Medium (2) & 10 & 9.4 & 2.91 & 0.29 \\
\hline & & & High (3) & 96 & 90.6 & & \\
\hline
\end{tabular}

Tobacco Cultivation Area of the Farmers: Tobacco cultivation areas were measured by the procedure mentioned earlier in the chapter 3.

The tobacco cultivation areas were ranged from 0.20 to 0.87 hectares with an average of 0.42 hectares and standard deviation of 0.11 . Based on observed range respondents were classified into three categories according to the tobacco cultivation area which is stated in Table 3. 
Table 3. Distribution of the respondents according to their tobacco cultivation area.

\begin{tabular}{lcc}
\hline Categories (hectares) & Number & Percentage $(\%)$ \\
\hline Small $(<0.40 \mathrm{ha})$ & 35 & 33.02 \\
Medium $(0.40-0.60 \mathrm{ha})$ & 65 & 61.32 \\
Large $(>0.60 \mathrm{ha})$ & 6 & 5.66 \\
Total & 106 & 100 \\
\hline
\end{tabular}

Data conferred in Table 3, revealed that $61.32 \%$ of the respondents had medium tobacco cultivation area followed by $33.02 \%$ of the respondents had small tobacco cultivation area and only 5.66 percent of the respondents had large tobacco cultivation area. According to the stated data it was observed that an overwhelming majority of the respondents were belong to small to medium (94.34\%) group of tobacco cultivation area. So, most of the farmers had few hectares of land to grow tobacco but they could not manage to expand their cultivation area though tobacco cultivation is profitable according to their perception.

The contribution of the selected characteristics of the framers to their determinants of extent of tobacco cultivation area in Kushtia District: To find out which factors directly contribute to the tobacco cultivation area, multiple linear regression analysis was executed. Table 4 conferred that age, education, annual income, and agent contact were the most important contributing factors (significant at $1 \%$ level of significance). Family labor was also an important contributing factor (significant at $5 \%$ level of significance) while farm size, tobacco cultivation experience, time spent in tobacco farming, profitability, input availability, level of pest infestation and market security had no significant contribution on farmers' tobacco cultivation area.

About $61.4 \% \quad\left(\mathrm{R}^{2}=0.614\right)$ of the variation in the respondents' tobacco cultivation area can be incumbent on their age, education, annual income, family labor and agent contact which generating this as an excellent model. The $\mathrm{F}$ value indicates that the model is significant $(p<0.000)$. Nevertheless, each variable may explain some the variance in respondents' tobacco cultivation area simply by chance. Although the addition of extraneous predictors in the model penalized by the adjusted Rsquare value $(0.546)$, it still indicates that variance in respondents' tobacco cultivation area can be incumbent on the predictor variables rather than by chance, and that both are suitable models (Table 4).

Table 4, multiple regressions co-efficient of independent variables related to farmers' tobacco cultivation area

\begin{tabular}{|c|c|c|c|c|c|c|c|c|c|}
\hline \multirow{2}{*}{$\begin{array}{l}\text { Dependent } \\
\text { variables }\end{array}$} & \multirow{2}{*}{$\begin{array}{l}\text { Independent } \\
\text { variables }\end{array}$} & \multicolumn{2}{|c|}{$\begin{array}{c}\text { Unstandardized } \\
\text { Coefficients }\end{array}$} & \multirow{2}{*}{$\begin{array}{c}\begin{array}{c}\text { Standardized } \\
\text { Coefficients }\end{array} \\
\text { Beta }\end{array}$} & \multirow[b]{2}{*}{$\mathrm{t}$} & \multirow[b]{2}{*}{ Sig. } & \multirow[b]{2}{*}{$\mathrm{R}^{2}$} & \multirow[b]{2}{*}{ Adj. $R^{2}$} & \multirow[b]{2}{*}{$\mathrm{F}$} \\
\hline & & $\mathrm{B}$ & Std. Error & & & & & & \\
\hline \multirow{12}{*}{$\begin{array}{l}\text { Tobacco } \\
\text { cultivation } \\
\text { area }\end{array}$} & Age & .005 & .002 & .324 & 3.045 & $.003^{* *}$ & \multirow{12}{*}{.614} & \multirow{12}{*}{.546} & \multirow{12}{*}{12.34} \\
\hline & Education & .010 & .004 & .252 & 2.781 & $.007^{* *}$ & & & \\
\hline & Farm size & -.040 & .023 & -.162 & -1.752 & $.083^{\mathrm{NS}}$ & & & \\
\hline & Annual income & .001 & .000 & .490 & 5.234 & $.000^{* *}$ & & & \\
\hline & Experience & .002 & .001 & .106 & 1.105 & $.272^{\mathrm{NS}}$ & & & \\
\hline & Family labor & .013 & .005 & .196 & 2.383 & $.019^{*}$ & & & \\
\hline & Time farm & .001 & .001 & .100 & 1.505 & $.136^{\mathrm{NS}}$ & & & \\
\hline & Profitability & .045 & .035 & .092 & 1.277 & $.205^{\mathrm{NS}}$ & & & \\
\hline & Agent contact & .002 & .001 & .284 & 3.064 & $.003^{* *}$ & & & \\
\hline & $\begin{array}{l}\text { Input } \\
\text { availability }\end{array}$ & -.043 & .045 & -.089 & -.957 & $.341^{\mathrm{NS}}$ & & & \\
\hline & Pest infestation & .012 & .011 & .083 & 1.124 & $.264^{\mathrm{NS}}$ & & & \\
\hline & Market security & .006 & .036 & .015 & .155 & $.877^{\mathrm{NS}}$ & & & \\
\hline
\end{tabular}


o had higher age, increased the tobacco cultivation. This implies that with the increase of age of the farmers will increase the tobacco cultivation. It may be because of most of the old aged farmers are not so much conscious about the harmful effects of tobacco cultivation as well as they are having lack of knowledge on soil, health and environmental problems. So, they do not really care about problems occurred by tobacco cultivation which leads them to cultivate tobacco in more area. The findings are similar to the study of (Bhavya, 2014; Abay, 2004; Beach et al., 2008).

Multiple regressions showed that education of the respondents brings a positive contribution to the tobacco cultivation. This implies that with the increase of education of the farmers will also increase their tobacco cultivation area. Education empowered one to get information through reading or listening and it has an effect on their income. It may be because of a farmer who is very educated is likely to get richer and improve their social livelihood status. That's why despite, knowing the harmful effects of tobacco cultivation educated farmers increase tobacco cultivation for getting higher income. The findings are similar to the studies such as (Rahman \& Parvin, 2017; Hassan et al., 2015; Bhavya, 2014; Mazikana, 2018; Chitongo, 2017; Halili, 1999; Hossain \& Rahman, 2013; Abay, 2004).

Multiple regressions showed that annual income of the farmers tremendously has a positive contribution for tobacco cultivation. This implies that with the increase of annual income will also increase the tobacco cultivation area of the farmers. It may be because of with the earning more income by tobacco leads farmers to cultivate tobacco on more lands. Although most of the farmers were well known about the harmful effects of tobacco cultivation, they only care about the profits and income they can manage. The findings are similar to the studies such as (Naher \& Efroymson, 2007; Beach, et al., 2008; Snell et al., 2009; Strader \& Alston, 2009; Chitongo, 2017; Mazikana, 2018).

Multiple regressions showed that agent contact of the farmers has a positive contribution for tobacco cultivation. This implies that with the increase of agent contact will also increase farmers' tobacco cultivation area. It may be because of tobacco companies' agents have a strong influence on farmers as they provide essential technical supports regarding tobacco cultivation. Also companies' agents maintain more contacts with large tobacco farmers providing them with seeds, fertilizers, insecticides and financial supports which directly motivate farmers to cultivate more tobacco. The findings is similar to the study of (Mazikana, 2018; Chitongo, 2017; Bhavya, 2014; Ali et al., 2015; Rahman \& Parvin, 2017; Hassan et al., 2015; Naher \& Chowdhury, 2002; Beach et al., 2008; Naher \& Efroymson, 2007; Akhter, 2011).

The analysis showed that family labor of the farmers brings a positive contribution to the tobacco cultivation. This implies that with the increase of family labor of the farmers will also increase the tobacco cultivation. It may be because of tobacco cultivation is a laborious work to do and family labor can give a huge support with no labor cost. Also during the curing of tobacco leaves family labor often works all day long without any cost which is efficient for any tobacco farmer. Therefore, more family labor support leads a farmer to cultivate more tobacco. The findings are similar to the studies such as (Bhavya, 2014; Abay et al., 2004; Naher \& Efroymson, 2007; Karagiannis \& Sarris, 2005; Rahman \& Parvin, 2017; Hassan et al., 2015; Kibwage et al., 2009; Obwona, 2006; Ali et al., 2015; Chikkala, 2015).

\section{CONCLUSIONS AND RECOMMENDATIONS}

Regarding area coverage by tobacco cultivation, the majority (61.32\%) of the farmers are in medium category. Therefore, initiative is necessary to bring most of the farmers under small group category. Age, education, annual income, agent contact and family labor of the tobacco farmers had a positive and significant contribution on their tobacco cultivation. It may be concluded that educated farmers want to improve their livelihood by earning much money as they believe that tobacco cultivation brings hard cash within a short period of time. As a large number of farmers had poor opportunity for education, arrangement should be made by the concerned authority to run more non-formal practical education and training to the farmers. This will help to expand their knowledge, skill, abilities and outlook which enable them to more profit from tobacco cultivation. The government may develop strategies to support tobacco farmers to diversify or to switch to more profitable crops as an alternative of tobacco to improve the farmers' livelihood. Therefore, it needs to further promote tobacco cultivation new technologies by designing an approach based on farmer's problem and need.

\section{REFERENCES}

Abay, C., Miran, B. \& Günden, C. (2004). An Analysis of 
Input Use Efficiency in Tobacco Production with Respect to Sustainability. The Case Study of Turkey. Journal of Sustainable Agriculture, 24 (3), 123-143.

Akhter, F. (2011). Tobacco Cultivation and its impact of food Production in Bangladesh, UBINIG. Retrieved from http://www.fairtradetobacco.org/wpcontent/uploads/2011/07/Farida-

Akhter_Tobacco-to-Food-Production.pdf.

Ali, M.Y., Islam, M.F., Rahman, M.R., Sheema, M.K. \& Akhtar, M.R. (2015). Tobacco Farming in Bangladesh and Its Impact on Environment. IOSR Journal of Environmental Science, Toxicology and Food Technology, 9(12), 27-33.

Bangladesh Bureau of Statistics (BBS). (2016). Agricultural Year Book of Bangladesh. Government of Bangladesh, Dhaka.

Barkat A., Chowdhury, A.U., Nargis, N., Rahman, M., Kumar, P.K.A., Bashir, S. \& Chaloupka. F. J. (2012). The Economics of Tobacco and Tobacco Taxation in Bangladesh, p6.

Bhavya, H.K. (2014). Socio-economic and environmental impact assessment of FCV tobacco cultivation in Karnataka. MS thesis, Department of Agricultural Economics, University of Agricultural sciences, Bangalore.

Beach, R.H., Jones, A.S. \& Tooze, J.A. (2008). Tobacco farmer interest and success in income diversification. Journal of Agricultural and Applied Economics, 40(1), 53-71.

Chikkala, K.K. (2015). Socio-economic Impact of Tobacco Cultivation on Dalit Agricultural Laborers: A Case Study from Andhra Pradesh, India. Journal of Developing Societies, 31(1), 77-97.

Chitongo, L. (2017). The Efficacy of Smallholder Tobacco Farmers on Rural Development in Zimbabwe. PhD thesis, Faculty of Natural and Agricultural Sciences, University of the Free State, Qwaqwa.

Dimara, E. \& Skuras, D. (1998). Adoption of new tobacco varieties in Greece: Impacts of empirical findings on policy design. Journal of Agricultural Economics, 19, 297-307

FAO. (2010). Projections of tobacco production, consumption and trade2010, https://ftp.fao.org/docrep/fao/006/y4956e/y49 56e00.pdf, (Food and Agriculture Organization of the United Nations (FAO), Rome, Italy), 2003, Retrieved on 10 January 2010.
Halili, R. (1999). Methods for Evaluating Agricultural Enterprises in the Framework of Uncertainty Facing Tobacco Producing Regions of Virginia. (Doctoral Dissertation).

Hossain, M.M. \& Rahman, M.M. (2013). A Socioeconomic Analysis on Tobacco Cultivation in Kushtia District of Bangladesh. Social Sciences, 2(3), 128-134.

Hassan, M.M., Parvin, M.M. \& Resmi, S.I. (2015). Farmer's Profitability of Tobacco Cultivation at Rangpur District in the Socio-Economic Context of Bangladesh: An Empirical Analysis. International Journal of Economics, Finance and Management Sciences, 3(2), 91-98.

Karagiannis, G. \& Sarris, A. (2005). Measuring and explaining scale efficiency with the parametric approach: the case of Greek tobacco growers. Journal of Agricultural Economics, 33, 441-451.

Kibwage, J.K., Odondo, A.J. \& Momanyi, G.M. (2009). Assessment of livelihood assets and strategies among tobacco and non-tobacco growing households in south Nyanza region, Kenya. African Journal of Agricultural Research, 4(4), 294-304.

Mazikana, O.M. (2018). The Socioeconomic Importance of Tobacco Production in Zimbabwe. MS thesis, Faculty of Regional Development and International Studies, Mendel University, Brno.

Motaleb, M.A. \& Irfanullah H.M. (2011). Tobacco cultivation in Bangladesh: is it a threat to traditional agro-practice. Indian Journal of Traditional Knowledge, 10(3), 481-485.

Naher, F., \& Efroymson, D. (2007). Tobacco cultivation and poverty in Bangladesh: issues and potential future directions. Dhaka: World Health Organization.

Naher, F. \& Chowdhury, A.M.R. (2002). To Produce or not to Produce: Tackling the Tobacco Dilemma. Research Monograph Series No. 23. BRAC Research and Evaluation Division Dhaka, Bangladesh.

Obwona, M. (2006). Determinants of technical efficiency differentials amongst small- and medium-scale farmers in Uganda: A case of tobacco growers. Economic Policy Research Centre (EPRC) Makerere University, Uganda. African Economic Research Consortium. AERC Research Paper 152.

Policy Research Institute of Bangladesh. (2012). Tobacco Cultivation: An Assessment of Socio-Economic and 
Environmental Impacts. Report by Policy Research Institute of Bangladesh (PRI) and Nielsen Bangladesh, commissioned by British American Tobacco Bangladesh.

Rahman, H. \& Parvin, J. (2017). Ethics and Economics of Tobacco Farming: A Case Study of Rural Bangladesh. IOSR Journal of Humanities and Social Science, 22(2), 56-65.

Sarkar, \& Haque. (2001). Tobacco Agricultural Research in Bangladesh in the 20th Century, Bangladesh Agricultural Research Council, Dhaka.

Snell, W., Powers, L. \& Halich, G. (2009). Tobacco
Economics in the Post-buyout Era. In 2009-2010 Kentucky and Tennessee Tobacco Production Guide. UT Extension Publication Number PB1782 (pp. 3-6). The University of Tennessee, Institute of Agriculture.

Strader, W. \& Alston, A.J. (2009). North Central Piedmont North Carolina Tobacco Producers' Views towards the Federal Tobacco Quota Buyout. Journal of Extension, 47(4).

Yearbook of Agricultural Statistics. (2016). Bangladesh Bureau of Statistics, Available from www.bbs.gov.bd.

Publisher's note: EScience Press remains neutral with regard to jurisdictional claims in published maps and institutional affiliations.

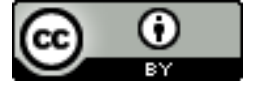

Open Access This article is licensed under a Creative Commons Attribution 4.0 International License, which permits use, sharing, adaptation, distribution and reproduction in any medium or format, as long as you give appropriate credit to the original author(s) and the source, provide a link to the Creative Commons license and indicate if changes were made. The images or other third-party material in this article are included in the article's Creative Commons license, unless indicated otherwise in a credit line to the material. If material is not included in the article's Creative Commons license and your intended use is not permitted by statutory regulation or exceeds the permitted use, you will need to obtain permission directly from the copyright holder. To view a copy of this license, visit http://creativecommons.org/licenses/by/4.0/. 